\title{
LAND USE MANAGEMENT ALONG URBAN DEVELOPMENT AXIS AS ONE OF URBAN REGENERATION PRINCIPLES
}

\author{
Somaya Aboelnaga ${ }^{1}$, Tamas Toth ${ }^{1}$, Gyoergy Ivan Neszmelyi ${ }^{2}$ \\ ${ }^{1}$ Szent Istvan University, Hungary; \\ ${ }^{2}$ Budapest Business School University of Applied Sciences, Hungary \\ somayanaga@cu.edu.eg, toth.tamas.argi@gtk.szie.hu,neszmelyi.gyorgy@uni-bge.hu
}

\begin{abstract}
Land management is one of the crucial issues for urban planning, which relates to the city's dynamic and also has a major effect on urban regeneration by creating a high demand for changing land use, especially in the previously developed land in urban and rural areas. In the frame of sustainable development, urban planners focus on Brownfield redevelopment to achieve effective mixed-use principles. As a matter of fact, The Regional and Urban Planning has an important part to play in tying opportunities for the developmental urban axis in integrated transport development and economic provision, as it can help concentrate development along and around rail and bus corridors rather than new roads. Therefore, there is a need for more than urban regeneration approaches to deal with urban development issues in the existing lands as urban corridors; as it works as the outcome of the sustainable development concept and phenomena has a relation to land use optimizing and management according to the urban regeneration principles. And one of the most effective tools is transitoriented development along the urban corridors. The research problem discussed in this paper is a strong conflict on land use and land management policies and strategies that make land use changing ineffective and leading to delays in the urban regeneration process. The research aim is to determine the land use management policy to transform the existing urban development corridors according to urban regeneration principles.
\end{abstract}

Keywords: land-use, management, regeneration, corridors, transit-oriented.

\section{Introduction - urban regeneration}

Urban regeneration is the culmination of the sustainable development concept. This phenomenon has a relation to land use optimizing and management according to urban regeneration principles. As shown in the literature, the urban regeneration principles are as following: (1) Establish a long-term vision; (2) Design for people; (3) Conserve cultural heritage; (4) Create integrated network; (5) Optimize land use; (6) Vitalize public space; (7) Foster collaboration; (8) Build healthy and sustainable communities; (9) Integrate economic development; and (10) Promote diversity- and make it beautiful [1]. It answers to the challenges of sustainable development in four main aspects: environmental (climate change, carbon emissions and resource use), social (inequality, cohesion and health), economic (job opportunities, investments), and institutional (governance and geographical disparities). This paper focuses on the transformation of the existing urban development corridors and as an instrument of land use optimizing and management in the frame of urban regeneration [2].

Land use optimizing is also rooted into spatial approaches such as 1) linking the spatial planning with comprehensive development plans (strategic planning); 2) public participation in the spatial planning; 3) integration of the spatial, environmental, economic and social issues in the planning process; 4) promotion of the "compact city" [3].

Land use and land management. Land system (use, management, ownership) is a key component of the land terrestrial ecosystem. Land use activities not only provided services such as the material products, but also brought profound land use/land cover changes (LUCC), which is an important element and one of the main reasons of global environmental changes. LUCC studies mainly focus on clarifying and analysing the driving mechanisms and characteristics of land use/cover change, forecasting and simulating future land-use change and spatial distribution [4].

\section{Materials and methods}

In the course of elaboration of the present study the research methodology we applied was the interpretation and understanding in a comprehensive way effecting of land management in urban regeneration, especially on the existing urban corridors. The novelty of our examinations also derives from the fact that, as far as we know it, we tried to give developmental recommendations for urban regeneration within the existing corridors based on transit-oriented development. The main method was qualitative research study through documents and reports reviews, with some case studies from the USA, Japan, and Egypt with the aim of determining the land use management policy to transform 
the existing urban development corridors according to the urban regeneration principles. Firstly, we had an overview on the definitions of urban regeneration and land management, in addition to approaches, driving forces, policies, strengths and weaknesses. Next, we focused on the existing urban development corridors through definitions, strategy, implementation and assessment, land demand and supply, and brown field versus green field development. Finally, we illustrated some policies guidelines of transit-oriented development.

\section{Results and Discussion}

\section{Land management for urban regeneration process}

Approaches to land management. There are many conceptions of the theory of planning, which can be summarized in four basic planning approaches: 1) rational-comprehensive approach is based on the scientific method, has five basic steps that focus on objectives, information, alternatives, impact assessment, and evaluation, 2) incremental approach, or what Lindblom (1959) called the "science of muddling through," accepts limitations in human knowledge and understanding, and as a result, focuses on short-term goals and objectives and small sequential actions. Adaptive planning is a modern- day form of incrementally. It recognizes the limitations on knowledge and aims to learn by developing the best plan within limits, implement the plan, monitor the results, and make changes based on monitoring, 3) participatory approach suggests that neither the rational- comprehensive nor the incremental approach deals explicitly with the diverse stakeholder perspectives and conflicting values. The participatory approach aims to inform and relate to the public in planning and decision making, and 4) advocacy approach recognizes that interested stakeholders do not speak with one voice, but often line up to entrenched camps and fight for their special interests. This situation often requires some advocacy of the underrepresented groups (such as the poor and values, such as natural) and mediation to resolve differences [5]. Urban planning generally requires a rational- comprehensive and participatory framework, with elements of adaptive-incremental management and advocacy planning as appropriate.

Role of the actors. The coreactors of land management are the planner and the private sectors. The role of the point of view of the planner; land use management can be reactive, proactive, or interactive. The complexity of land use problems requires interdisciplinary solutions. Land management is an exceptional driving field, borrowing heavily from several disciplines, including natural science and engineering, economics, law, politics, and ethics. However, the actors are driven by the urban planner; growing interest in environmental and sustainability issues has added some new participants of the process and new disciplinary perspectives, which have further increased the diversity and complexity of the field. Planners are often grounded in a discipline, but as generalists, they must understand and implement a range of disciplinary perspectives to the planning process [6].

The role of the point of view of the private sector; land use and land management (LULM) decisions are most often driven by private economic interests that do not have to align with the interests of society. Landowners earn financial returns by producing marketed goods (e.g., agricultural crops, timber) but not for producing non-marketed public goods (e.g., improving water quality, providing habitat for species, or sequestering carbon). As a result, landowner actions often deliver high levels of marketed goods, but do not offer the levels of water quality protection, species habitat protection, carbon sequestration, and other non-marketed ecosystem services that society desires [6].

Driving forces. The driving force for land use management and planning is cantered around: the need for a change, which means the current situation is unwanted and the local community has needs and requirements, need to improve management which seeks to implementation and monitoring process, and the need to get a different practice of land use according to changing the state of affairs [7].

Policies, strategies and actions. Land use management activities are profoundly influenced by the land use policy through the guidance, regulation and distribution functions, which are one of the most fundamental driving factors of ecosystem services change, one of the most imperative factors that makes change in land management. Furthermore, ecosystem services are the carrier of human wellbeing. Therefore, simulation of land use policy can realize more accurate forecasting and analysis of the policy implementation results. It is conducive for policy makers to formulate appropriate policies, 
decrease the risk and costs of policy implementation, and then help promote health and long-term socioeconomic development [8].

Policy simulation of land use optimization is generally defined as a decision support system for government services, whose goal is to seek appropriate policies responding to the future development and discover policies considering possible socioeconomic shock. Furthermore, policy simulation refers to virtual testing of policy problems based on mathematical modelling and computer simulation technology. This kind of simulation and experiment could be classified into two cases. One is to be able to verify a variety of policies to determine the optimal policy. The other is to be able to simulate a single policy role under complex policy environment to understand the policy effectiveness. Policy simulation includes mathematical modelling, algorithms, computer modelling and simulation, decision support, etc. With the advancement of computer science and technology, policy simulation has been widely utilized in the energy policy, agricultural and forestry policy, population policy, financial policy, innovation policy and other fields [9].

Optimization of land uses policy simulation focus on a virtual test involving land use policy scenarios and simulation. Based on computer technology and mathematical modelling, it is used for ecosystem service improvement [8].

Land use regulation or development management: Most decisions on development should be made at the local level based on criteria (decision rules) set out in the policy documents (including the framework plan) adopted by the local authority after consultation with higher levels of the government. There should be a procedure that requires all those (including all public bodies) intending to undertake development to obtain authorization from the local authority. There should be also possible a requirement for each of those sectoral interests to be consulted about particular decisions. However, the system overall should emphasize that local decision and should be strongly directed by agreements reached among sectoral interests at regional and framework levels. Inevitably, there will be proposals that are not shown in strategies and plans [6].

The most vital recommendations of proposed implementation strategies for sustainable land use management are as follow [6]:

- Support the role of land resources within the boundaries of their capacities.

- Ensure that land use is confirmed by appropriately located and timed monitoring for land condition and trend.

- Establish the linkages between sustainability and profitability.

- Provided for in the protection and preservation of the region's valuable natural resource assets.

- Incorporate Native Title interests into land use planning procedures.

- Identify and recognise mining, petroleum and extractive resources, including hard rock quarry resources, and their economic potential, ensuring sites and access to them, protect against incompatible land uses, and impacts associated with their extraction are kept within socially and environmentally acceptable limits.

- Restore land uses capability and ecosystem function of degraded areas for improved viability and community welfare.

- Identified land of strategic importance for regional open space benefit from the protection and made do for future generations.

Processes. The general process of planning, which is so important in the urban regeneration frame and scopes it on implementation land use optimization, can be identified as the following steps [5]:

- Scooping (Stakeholder Issues); Scope out fundamental issues, stakeholders, opportunities for participation, needs for conflict resolution, and needs for data and analysis; draft preliminary work program for the process; draft preliminary design for stakeholder engagement and participation.

- Identification of issues, opportunities, concerns, objectives, criteria, uncertainties (Stakeholder Criteria); identify IOC (issues, opportunities, concerns), evaluative factors, including institutional, legal, technical criteria; participation tools (advisory committees, 
meetings, workshops, surveys) determined by scooping; conflict resolution and negotiation tools (advocacy) depending on degree of controversy.

- Analysis of planning situation (Stakeholder Local Knowledge); range of information gathering, and analysis determined by evaluative factors; identify data limitations and uncertainties; participation tools (workshops, surveys); conflict resolution and negotiation tools (advocacy) depending on the degree of contention.

- Formulation of alternatives (Stakeholder Alternatives); scope of alternatives (comprehensive, incremental) determined by the LOC, planning situation, degree of uncertainty (adaptive), participation tools (workshops, workbooks, surveys).

- Assessment of impacts (Stakeholder Assessment); economic, environmental, and social effects; scope of assessment (comprehensive, incremental) depends on evaluative factors planning situation, and alternatives; Impact assessment tools (cost-benefit, environmental impact assessment (EIA), social impact assessment (SIA); participation tools (workshops, surveys).

- Evaluation and selection of plan (Stakeholder Evaluation); organization and evaluation tools (matrices, etc.); participation tools (workshops, surveys, review and comment); conflict resolution and negotiation tools (advocacy) depending on the degree of controversy.

- Implementation, monitoring, post implementation evaluation, modification (adaptive) (Stakeholder Implementation); timing and extent of monitoring and modification (adaptive) determined by level of uncertainty and degree of controversy; participation tools (citizen monitoring, workshops, annual conferences) determined by level of uncertainty and degree of controversy.

\section{Strengths and weaknesses}

Strengths. The process of land use optimizing is an essential instrument in land use development policies implementation. It has many positive aspects of strengths which make the projects effective that can be summarized as follows [10]:

- The land use planning and analysis system that has been developed and its component modules are application-oriented. They are designed to be able to determine future possibilities and limitations and to explore consequences of different land use priorities.

- The systems approach developed fosters interdisciplinary research and the organizational structures for holding.

- There is good collaboration between the provincial projects, based on common goals.

- By the nature of the outputs and the intended users, the project offers an opportunity to establish direct links between researchers and policymakers.

- Apart from its other advantages, as a means to resolve compositeland use problems, the systems approach developed has empirical value in that it promotes and facilitates selfteaching. In building the system to represent part of the real world, a research scientist is obliged to make assumptions, and these highlight points where understanding or data are deficient, which in turn focuses attention on the areas where further research is necessary.

- The project has taken a significant scientific contribution in the form of publications of high quality.

- The development of tools and the mode of application have been extensively documented[11].

Weaknesses. However, one should also take into consideration limitations or weaknesses of the project's outputs, which can be summarized as follows [10]:

- While the project promised to address very broad issues of land use planning, the land use planning and analysis system currently developed focuses on a smaller set of issues, restricted to generation of options for agricultural land use at the regional (sub-national) level for an unspecified time in the future.

- The outputs from the optimization program are definite objective solutions; there is currently no means of reaching a consensus among stakeholders for assigning weights to conflict objectives.

- There is not any provision yet for a time dimension in optimization solutions. 
- The three aspects just listed limit the range of "what-if?" Questions that can be explored.

- The land use planning and analysis system outputs as currently presented are difficult for stakeholders to comprehend.

- The analysis does not offer details of what needs to be done to achieve the desired goals.

- The data available are often limited and of doubtful quality.

- There is always a need to validate models.

- At present the land use planning and analysis system models can handle data on bio-physical characteristics much better than socio-economic data [11].

\section{Existing urban development corridors}

The urban development corridor has great effect on the city development process, that is the reason why we focus here in this paper on discussing it in the frame of urban regeneration.

Definitions. The corridors are simply defined as natural or induced linear areas linking patches, districts, and cities; and to provide secure habitat conditions for migration from one core reserve to another. This research focuses on the existing urban development corridors between the cities. And there are many planning principles for corridors, state as follows: 1) continuous corridors are better than fragmented corridors; 2) wider corridors are better than narrow corridors; 3 ) natural connectivity should be maintained or restored; 4) two or more corridor connections between patches (redundancy) are better than one. Thus, urban development corridors can be recreational corridors, natural or ecological corridors, historical and cultural corridors, controlling corridors (green belt), and comprehensive corridors [5].

Strategy, implementation and assessment. The plan for further development of the existing urban corridors seeks a new urban form that includes more intensive forms of urban development along the main road corridors. By delivering a more intensive form of development along corridors, Greater Adelaide will be able to create a more compact urban form for the remainder of the city and its region and decrease further urban sprawl. New transit corridors, growth areas, transit-oriented developments and activity centres [12].

Feasibility and implementation; there are some enormous benefits from the corridors, such as environment, education, aesthetic, recreation and transportation, social and health, and economic benefits [12]. There are several assessment tools and methods, which could be used to evaluate the proposed strategy of transformation of urban corridors such as: land use /transport interaction model strategy, the environmental assessment geographic, information system economics, and financial assessments engineering feasibility. Assessment Framework: objective achievement, problem amelioration (both including environmental impacts), economic value for money, equity, financial sustainability [13].

Land demand and supply. Therefore, land demand and supply are the focal factors of transformation of the urban corridors in most of the world metropolitan areas. In a regional context, growth in the metropolitan areas is expected to be bright and substantial in overall growth rates. Demand for housing has steadily increased, while the supply has been reduced. Demand has been fuelled by a steadily increasing growth rate. To support the growth tendency of population, how much additional dwellings will be required each year. These areas have also seen a rise in housing approvals, and improvements to infrastructure will make the region more attractive [14].

"Therefore, strong land price increases can at least be partially addressed by a substantive increase in the supply of land. The supply of housing land and competition in the residential market provided. The role in supplying land and satisfying demand must be considered within the context of strategic growth. It is considered that establish new housing in the suburbs is an ambitious target. However, it may be possible to improve the land supply of infill sites in established areas, if appropriate renewal sites are found, and the creation of TODs is successful" [14].

One can describe telling the principle to plan urban corridors in such a way they will support the urban regeneration process; they will draw in more infrastructure, employment and services, providing a catalyst for the creation of additional suburbs. And also, will accommodate a different range of neighbourhood and dwelling types at different densities. In addition to provide housing, which suits a range of people and households in different age and income brackets, so a range of housing types 
(large detached housing, attached housing, apartments and shop top housing), and the accessibility to centres and public transport [14].

Brownfield vs. Greenfield development. Smart Growth, New Urbanism, and regional approaches aim to accommodate development within urbanized centres and to conserve natural environments and agricultural lands outside developed areas. Planners have coined several clever labels or "fields" to characterize the appropriateness for development within this target [5].

- Brownfields are considered to be vacant, potentially contaminated areas within urban centres that are difficult to produce because of suspected financial and environmental hazard. Brownfield redevelopment is beneficial, because it cleans up suspected contamination, improves central urban property values and avoids the development on Greenfields outside the metropolis.

- Greenfields are open, natural, or agricultural lands that provide natural amenities, wildlife habitat, natural system benefits, resource production, and community character. New development often converts Greenfields to urban purposes. Environmental planning and design emphasize development that minimizes impact on Greenfield benefits or avoid them all. Infields, like Brownfields, are vacant urban areas available for infill development and redevelopment, but they do not present environmental risks. With existing development infrastructure and a minor risk of environmental impact, they are far more desirable for developmental impact. They are far more desirable for development than Greenfields.

- Greyfields are vacant or non-profitable older suburban commercial centres and parking lots that are prime for renovation. Converting such sites to community centres can bring muchneeded civic space to the suburban areas. Finally, brighfields describe parking lots and other large asphalt expanses available for energy production using solar photovoltaic systems that double as shading devices.

\section{Transit oriented development}

From the point of view land use management the Transit Oriented Development (TOD) can be one of the most applicable tools to introduce the urban regeneration process. TOD has been promoted for more than 20 years in numerous cities of the world as a sustainable urban mobility policy. New transit corridors, growth areas, transit-oriented developments and activity centres [15].

There are several policies guidelines needed to be taken in consideration while using the Transit Oriented Development (TOD) $[15 ; 16]$.

- Designate and protect transit corridors, so a significant amount of net dwellings growth and net jobs growth can be generally located within 800 metres of a major transit corridor or within 400 metres of other transit corridors.

- Designate five fixed-line transit corridors as state significant areas. The Department of Planning and Local Government will prepare Structure Plans for these corridors in partnership with other state government agencies and local government.

- Prepare Structure Plans for transit corridors to determine in the earlier process the types of land uses allowed to avoid the need for individual rezoning of major sites.

- Concentrate higher densities and medium rise development around mixed-use activity centres and railway, tram and bus stations.

- Ensure that there is an effective transition between higher densities and medium rise development (near shops and stations) and existing low-rise detached housing. Structure plans for transit corridors will prescribe that densities and building heights decrease as development moves away from transport thoroughfares, shops and railway stations. This will mean that traditional detached dwellings will generally be bordered by low-rise dwellings such as townhouses.

- Define transit corridors by unique design and character guidelines, giving each corridor a separate identity to avoid a monoculture of building styles across the area.

- Ensure transit corridors contain a network of cycle ways, walkways and greenways to provide cooling and to create liveable and attractive locations for a diverse population. 
It is also vital to mention the specific targets for the upcoming plan, such as providing a net contribution of active and passive open space in transit corridors. And also locating more than $50 \%$ of net dwellings growth (including transit-oriented developments and sites that incorporate these development principles and design characteristics) and about $35 \%$ of new jobs in transit corridors [15].

\section{Case studies}

South Lake Union, Seattle, USA. In the late 1990s, revitalizing the nearly 24-hectare commercial and industrial neighbourhood of South Lake Union into a vibrant mixed-use community seemed like a questionable plan [1]. The main objectives were focused on setting the stage for redevelopment, initial investments catalyse development, improving the mobility, and liveability, of South Lake Union, promoting affordability and sustainability, provide more transportation choices, promote equitable, affordable housing, enhance economic competitiveness, supporting existing communities, and coordinate policies and leverage investment [17]. Fresh off the dot-com bust, Seattle was wary of seemingly easy fixes. But one of the key stakeholders saw the potential for the site and started acquiring land and convincing the local government and residents of it. A public-private partnership between city offices and investors and other funders led to the blooming neighbourhood that South Lake Union is today. Significant private funding drove the project, while new laws that changed the land use codes to provide for the construction of research laboratory buildings and offered tax breaks to encourage building affordable housing helped it along. The city's design guidelines assured the quality of the development by identifying "heart locations" of commercial and social centres; managing the transition of scale between varying building types; requesting durable, maintainable, and attractive exterior materials; and designing to respond to the "working class, maritime, commercial, and industrial character" of select areas.

Today the eclectic mix in South Lake Union includes centres for biotechnology, information technology, and global health; dozens of shopping, eating, and drinking venues; headquarters for Amazon; the Museum of History \& Industry; hotels; apartments; yoga centres; a streetcar line to downtown, and more. From 2004 to 2010, South Lake Union added 590,000 square meters of spaces; 13,647 permanent jobs; over 35 million USD in tax revenue; and 1 billion USD to its assessed value. Intensifying its land use can need to be measured in more than numbers [1].

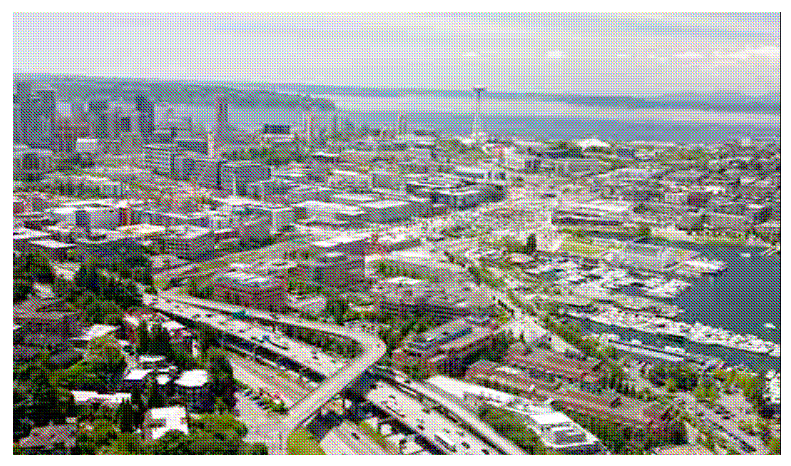

Fig. 1. South Lake Union, Seattle, USA [1]

Namba Parks, Osaka, Japan. In the late 1990s, Osaka, like much of Japan, was suffering from a nationwide recession. In addition, some of the city's companies and research institutes had relocated to Tokyo, affecting the citywide economy. Namba Parks, a 3.4-hectare mixed-use project, led Namba District's 21-hectare redevelopment project. The site of Namba Parks had been underused; a baseball stadium sat dormant on an irregular shaped lot framed by a busy train station and a 1957 shopping centres [1]. The Class A office spaces are 91 percent occupied, tracking the Osaka market, which is recording 93 percent occupancy for Class A space and 90 percent occupancy throughout the city's CBD. The tower's rental rates represent a premium for its 28 levels of uninterrupted, large-floor-plate space (14 by 64.8 meters) [18]. Nankai Electric Railway and Takashimaya department store jointly improved the site, and Jerde Partnership responded with a canyon-like, eight-story retail and entertainment centre, which links directly to a subway line and parking beneath it. The "parks" in its name refer to 1.2 hectares of green terraces that cascade down the centre's roofs and provide both public space and outdoor restaurant seating. The park's greenery - trees, shrubs, ponds, and planting 
beds - helps in cooling. In the summer, when local asphalt surfaces reach 51 degrees Celsius, the park is only 34 . A thirty-story office tower by Nikken Sekkei creates a new anchor at the plot. Namba Parks provided 245,000 square meters of retail, entertainment, office, residential, cultural, parking, and common space in two phases, and has become instrumental to the 2003 Osaka City Revitalization Program, "designed to develop academic and business-related growth, develop the cultural pull of the city and ensure attractive and vibrant communities were related" [1].

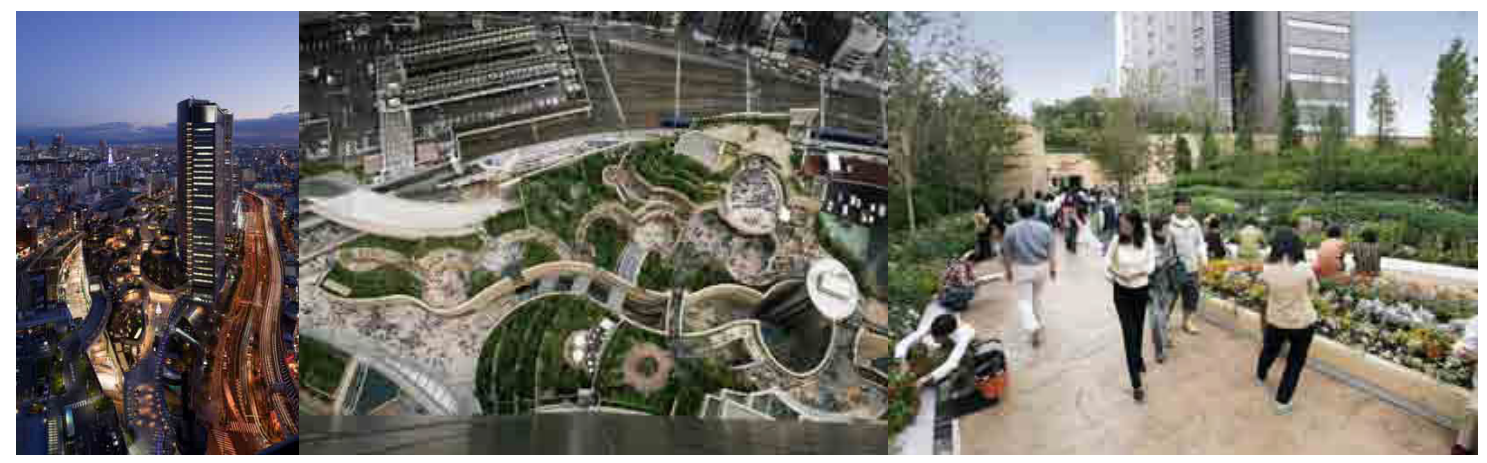

Fig. 2. Namba Parks, Osaka, Japan [1]

Maspero Triangle Development, Cairo, Egypt. One of the most luxurious values of land in Greater Cairo, connected very well with all transportation systems and also located along the Nile near to branding hotels in the city centre. However, behind that beauty of the Nile and waterfront, there is an informal area of the planners, investors and government need to develop and improve the quality of life in this area. Thus, the government announced on competition to redevelop Maspero Triangle Development as one of urban regeneration projects in Cairo implementation stage the government and investors have faced the community who resists leaving their place at first. The Slum Development Fund is the agency, which is responsible to deal with the community, and they start at first to determine the key actors from the community, who will be an active partner in all possible initiatives, pushing for the community-oriented solutions at every stage and scale. To achieve the goals and strategies from the participation; to have a representative and leader being partners in communication with all process participants, to make community visible and important, to raise the selfconsciousness, to participate as a partner in key city development projects [19]. As the report of the Slum Development Fund (2017) illustrates the social survey to show the desire of leaving or staying in the area after development, ( $85 \%$ of the families voted and participate in the survey) it comes as follows:people, who want to leave $77 \%$, and people, who want to stay $22 \%$, and $1 \%$ of the families refused the project. The people who decide to leave were divided into two groups, $4 \%$ moved to AlAsmarat (new area established to have the people from the informal areas well designed and well planned), and the rest of people who will leave $73 \%$ decided to get financial compensation[20]. Regarding the people, who want to stay most of them have commercial units along $15^{\text {th }}$ of May extension corridor, one of extreme frequently visiting areas for shopping [19].

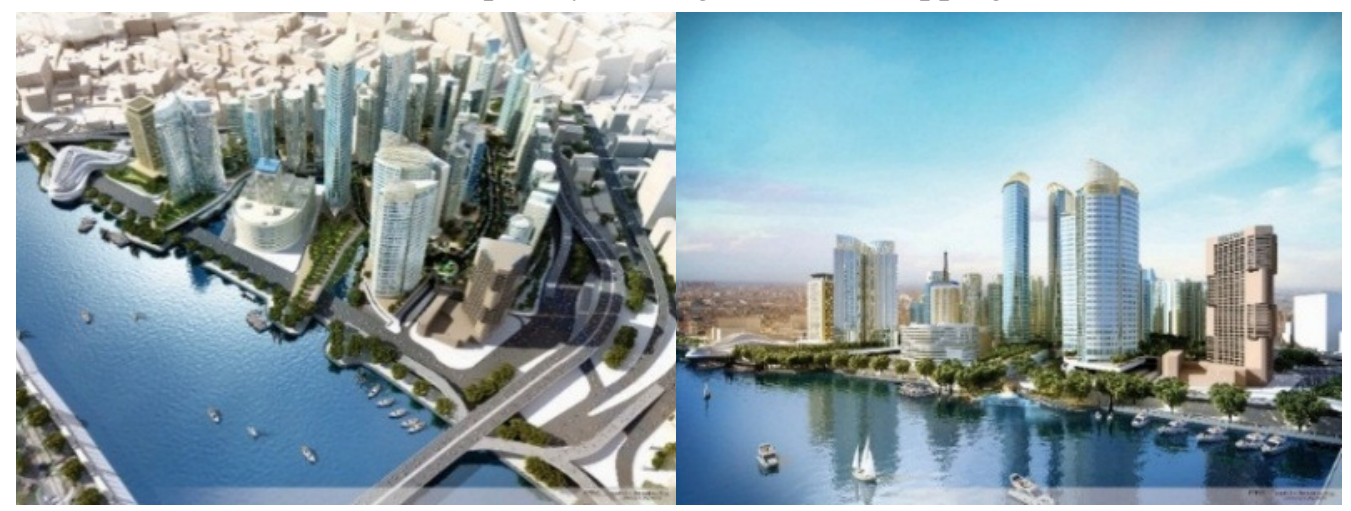

Fig. 3. Maspero Triangle, proposed perspectives [20] 


\section{Conclusions}

The conclusion of this study is centred on land use optimizing and management as concepts, along the urban corridors as space, using the transit-oriented development as a tool all in the frame of urban regeneration. Especially, for enhancing an effective transition between higher densities and medium rise development (near shops and stations) and existing low-rise detached housing. Moreover, structuring plans for transit corridors will prescribe that densities and building heights decrease, as development moves away from transport thoroughfares, shops and railway stations. This will mean that traditional detached dwellings will generally be bordered by low-rise dwellings such as townhouses.

The similarity in cases is the site potential. That can be used to redevelop the area by supporting the private sector to fund for the land use optimizing in the frame of urban regeneration process. As a conclusion for the case studies; they are similar at the location, as they are either in CBD or close to $\mathrm{CBD}$, on the land use category as mixed land use, and on the social context decision as partnership in between public and private. On other hand, the differences are related to the concept of developing the areas. So, we can find it is mobility competitiveness at South Lake Union, redevelopment transitoriented development at Namba Parks, and redevelop regeneration at Maspero Triangle.

\section{References}

[1] ULI , "Ten Principles for Urban Regeneration Making Shanghai a Better City," ULI Asia Pacific, Hong Kong, 2014.

[2] Tsenkova S. "URBAN REGENERATION Learning from the British experience," University of Calgary, Calgary, Canada, 2002.

[3] Huston S., Rahimzad R. Parsa A., “'Smart' sustainable urban regeneration: Institutions, quality and financial innovation," Cities, 2015, p. 10.

[4] Albrechts L. "Strategic (spatial) planning reexamined," Environment and Planning B: Planning and Design, 2004, pp. 743-758.

[5] Randolph J. Environmental Land Use Planning and Managment, Washington, DC: Island Press, Suite 300, 2011.

[6] WGEA, "Land Use and Land Management Practices in Environmental Perspective," INTOSAI Working Group on Environmental Auditing (WGEA), www.environmental-auditing.org , 2013.

[7] Aboelnaga S. "Approach of national and regional land use planning - in Egypt," Cairo University, Cairo, 2016.

[8] Munroe D., Croissant C., York A. "Land use policy and landscape fragmentation in an urbanizing region: Assessing the impact of zoning," Applied Geography, 2005, pp. 121-141.

[9] Matta A. "Sustainable Development Indicators for Land Use in Santiago, Chile," Chalmers University of Technology, Göteborg, 2008.

[10] Roetter R., Keulen H. V., Laborte A., Hoanh C., Laar H. V. "Systems research for optimizing future land use in South and Southeast Asia," International Rice Research Institute, Los Baños, Philippines, 2000.

[11] Hendroyono B., Supriyono B., Wijaya A. F., Muhammad F. "Strength, Weakness, Opportunity, and Threat (SWOT) of the Implementation of HTR Policy in Indonesia," Journal of Law, Policy and Globalization, 2015, pp. 23-30.

[12] Indian Institute for Human Settlments, "Urban Corridors: Strategies for Economic and Urban Development," International Growth Centre, London, 2015.

[13] Bina O. "Strategic Environmental Assessment of Transport Corridors: Lessons learned comparing the methods of five Member States," European Commission, DG Environment, London, 2001.

[14] W. C. \&. DAYCORP, "Land supply and demand analysis," Connor Holmes, 2009.

[15] Sivakumar A. "Modelling transport: A Synthesis of Transport Modelling Methodologies," Imperial College, London, 2007.

[16] South Australian Planning Policy Library, "Urban Corridor Zone," South Australian Planning Policy Library, South Australian, 2011.

[17] HUD, DOT, EPA, “Seattle's South Lake Union Neighborhood," Sustainable Communities , 2012.

[18] ULI , “ULI Development case studies,” ULI, Osaka, Japan, 2005. 
[19] Aboelnaga S. "Public participation in planning in the Egypation context," in International Scientific Conference, Role of citizen participation in the formation of the city, Warsaw, 2017.

[20] Slum Development Fund, "Maspero Triangle Development," Slum Development Fund, Cairo, 2017.

[21] United Nations, "SPATIAL PLANNING Key Instrument for Development and Effective Governance with Special Reference to Countries in Transition," United Nations, Geneva, Switzerland, New York and Geneva, 2008.

[22] Koresawa A., Konvitz J. Towards a new role for spatail planning, Paris: OECD, 2001.

[23] Nguon R., Diepart J.-C. "Scaling the landscapes: a methodology to support integrated subnational spatial planning in Cambodia," in XXIV FIG 2010 conference: Facing the Challenges-Building the Capacity, Sydney, 2010. 